TẠP CHÍ KHOA HỌC ĐẠI HỌC TÂN TRÀO

ISSN: $2354-1431$

http://tckh.daihoctantrao.edu.vn/

\title{
Vận dụng cặp phạm trù nguyên nhân - kết quả phân tích vấn đề ô nhiễm môi trường ở Việt Nam
}

\author{
Trần Bảo Nguyên ${ }^{a^{*}}$, Đuờng Huyền Trang ${ }^{a}$ \\ ${ }^{a}$ Trưòng Đại học An Giang \\ *Email: tbnguyen@agu.edu.vn
}

\section{Thông tin bài viết}

Ngày nhận bài:

$02 / 8 / 2018$

Ngày duyệt đăng:

$10 / 9 / 2018$

Tù khoá:

Môi trường, ô nhiếm, mối quan hệ, nguyên nhân, kêt quả.

\section{Tóm tắt}

Bảo vệ môi trường là một vấn đề trước mắt và có ý nghĩa to lớn cho sự phát triển bền vững và tương lai của nhân loại. Bài báo dựa trên mối quan hệ "nguyên nhân - kết quả", tập trung vào phân tích các nguyên nhân gây suy thoái môi trường và chỉ ra các vấn đề tai hại do ô nhiễm môi trường. Kết quả nghiên cứu cho thấy rằng các yếu tố tự nhiên, sự thiếu ý thức của con người trong sản xuất và sinh hoạt, những tàn tích từ chiến tranh để lại chính những nguyên nhân chủ yếu gây ra ô nhiễm môi trường. Và theo quy luật, môi trường ô nhiễm sẽ tác động trở lại con người, chúng ta sẽ phải đứng trước các nguy cơ về sức khỏe, sự thiếu hụt tài nguyên, thiệt hại nặng về kinh tế, đất nước chậm phát triển. Từ đó, các giải pháp của vấn đề gây ra ô nhiễm môi trường có thể được đưa ra và thảo luận.

\begin{abstract}
1. Mở đầu
Nhân loại từ thuở sơ khai đến hiện tại và trong tương lai luôn khát vọng được sống trong sự bình an, hạnh phúc và tận hưởng một môi trường trong sạch. Khát vọng đó càng trở nên cấp thiết hơn trong bối cảnh môi trường sống đã, đang và sẽ ngày càng bị đe dọa nghiêm trọng, trở nên xấu hơn bởi những tác động mạnh mẽ từ mặt trái của quá trình phát triển kinh tế xã hội không đồng đều.
\end{abstract}

Bảo vệ môi trường luôn có một vị trí quan trọng trong các chính sách, chiến lược phát triển của quốc gia. Các vấn đề môi trường tại Việt Nam báo động điều đáng lo ngại rằng mọi người đang tự làm hại chính mình theo cách gián tiếp thông qua việc tác động tiêu cực đến môi trường bằng các hoạt động sản xuất và dân sinh. Hoặc trong những hành động vô thức hằng ngày tưởng chừng vô hại nhưng lại ảnh hưởng không nhỏ đến sự trong sạch, phát triển bền vững của môi trường.

"Môi trường đang bị hủy hoại như thế nào?", "Biện pháp nào giúp bảo vệ môi trường trước những hiểm họa?” - đây là những vấn đề nhận được sự quan tâm sâu sắc của mọi quốc gia và cả nhân loại. Để cứu vãn tình hình môi trường ngày một xuống cấp trầm trọng, nhiều cuộc hội nghị, hội thảo, đề tài nghiên cứu của các nhà khoa học trên khắp thế giới được tiến hành nhằm truyền đi những thông điệp giá trị về bảo vệ môi trường, kinh tế xanh... Đồng thời, kêu gọi mọi người chung tay góp sức bảo vệ môi trường bằng việc nhận thức được nguyên nhân và kết quả cốt lõi của vấn đề.

\section{Cơ sở lý thuyết}

\section{1. Ô nhiễm môi trưòng là gì?}

Theo Luật Bảo vệ Môi trường của Việt Nam: “Ô nhiễm môi trường là sự làm thay đổi tính chất của môi trường, vi phạm Tiêu chuẩn môi trường".

Trên Thế giới, ô nhiễm môi trường được hiểu là việc chuyển các chất thải hoặc năng lượng vào môi trường đến mức có khả năng gây hại đến sức khoẻ con người, đến sự phát triển sinh vật hoặc làm suy giảm chất lượng môi trường.

2.2. So lự̛c về cặp phạm trù nguyên nhân - kết quả

2.2.1. Khái niệm nguyên nhân - kết quả 
Nguyên nhân và kết quả là một cặp phạm trù trong phép biện chứng duy vật của chủ nghĩa Mác - Lênin. Như vậy, theo chủ nghĩa Mác - Lênin thì:

Nguyên nhân dùng để chỉ sự tác động lẫn nhau giữa các mặt trong một sự vật, hiện tượng hoặc giữa các sự vật, hiện tượng với nhau thì gây nên một biến đổi nhất định. Nguyên nhân được sinh ra bởi các yếu tố tác động bên ngoài hoặc sự biến đổi từ bên trong sự vật, hiện tượng.

Kết quả dùng để chỉ những biến đổi xuất hiện do sự tác động giữa các mặt, các yếu tố trong một sự vật, hiện tượng, hoặc giữa các sự vật, hiện tượng tạo nên.

2.2.2. Đặc điểm mối quan hệ biện chứng giữa nguyên nhân - kết quả

Nguyên nhân sinh ra kết quả, cho nên nguyên nhân bao giờ cũng có trước kết quả, còn kết quả bao giờ cũng xuất hiện sau nguyên nhân.

Một nguyên nhân có thể sinh ra một hay nhiều kết quả, và một kết quả có thể do một hoặc nhiều nguyên nhân tạo nên.

Nguyên nhân sinh ra kết quả, nhưng kết quả không hoàn toàn thụ động, nó vẫn có khả năng tác động trở lại nguyên nhân.

Nguyên nhân - kết quả có thể hoán đổi vị trí cho nhau.

3. Phân tích vấn đề ô nhiễm môi trường ở Việt Nam trong mối quan hệ nguyên nhân - kết quả

\subsection{Nguyên nhân}

Cho đến nay, các nghiên cứu về môi trường đều chỉ ra được nguyên nhân dẫn đến thực trạng ô nhiễm, có cả nguyên nhân khách quan và chủ quan; trong đó tập trung chủ yếu vào các nguyên nhân sau:

Thư nhất, do chính sụ vận động môi trừng tụ chuyển hóa hình thành các tác nhân:

Môi trường là một thể thống nhất, tồn tại phụ thuộc vào nhiều yếu tố và có sự tác động qua lại giữa chúng. Trong quá trình vận động, bất kỳ một yếu tố nào trong môi trường tự nhiên thay đổi bất thường cũng sẽ ảnh hưởng đến tổng thể chung, tốt hay xấu sẽ phụ thuộc vào khuynh hướng mà chúng thay đổi. Cụ thể, nếu chúng thay đổi theo hướng tiêu cực thì môi trường sẽ trở nên xấu dần và kết quả là bị ô nhiễm. Ô nhiễm do các yếu tố tự nhiên có thể rất nghiêm trọng, nhưng không thường xuyên và không phải là nguyên nhân chính gây suy giảm chất lượng môi trường nhưng cũng không thể loại trừ.

Thư hai, ý thức cá nhân trong bảo vệ môi trưòng còn rất kém:

Theo một số quan niệm triết học duy xã hội các triết gia phương Tây về mối quan hệ giữa vật con người với thiên nhiên, con người luôn đặt mình là trung tâm của vũ trụ, là chúa tể của giới tự nhiên, có khả năng sáng tạo và có quyền thống trị giới tự nhiên. Những quan niệm đó là cơ sở hình thành tư tưởng con người được toàn quyền chinh phục tự nhiên theo kiểu "thống trị”, "tước đoạt" và “cư xử tệ" với môi trường tự nhiên, từ đó để lại những hậu quả môi trường to lớn. Những hành động vứt hoặc xử lý rác thải tùy tiện, không đúng quy định, phóng uế bừa bãi... không còn xa lạ với chúng ta. Những hành động đó tuy nhỏ bé nhưng vô cùng nguy hại và đang từng ngày phá hủy môi sinh nghiêm trọng nếu diễn ra liên tục, kéo dài. Bên cạnh đó, trong tiềm thức của con người chỉ coi tài nguyên thiên nhiên như một nguồn cung cấp vật chất cho nhu cầu sống và thu nhập, xem các khía cạnh xung quanh vấn đề môi trường chỉ là thứ yếu. Thực chất, nếu để dưỡng nhân thì tài nguyên thiên nhiên vẫn đủ khả năng đáp ứng nhưng vì sự vô minh, lòng tham chi phối và mưu cầu tiền bạc mà con người bỏ ngoài tai những lời kêu cứu từ môi trường. Như vậy, môi trường bên ngoài ô nhiễm trầm trọng chính vì môi trường trong ý thức con người đang bị xuống cấp.

Thư ba, thiếu trách nhiệm bảo vệ môi truoòng trong tổ chức các hoạt động sản xuất, kinh doanh:

Chúng ta không thể phủ nhận rằng, trước khi chuyển sang nền kinh tế thị trường, môi trường tự nhiên nước ta đã bị tàn phá. Song, từ khi phát triển nền kinh tế thị trường, môi trường tự nhiên bị tàn phá nhanh hơn, với quy mô lớn hơn. Bởi lẽ, trong kinh tế thị trường, những lợi ích kinh tế ngắn hạn đã làm cho con người bị cuốn vào dòng xoáy các hoạt động kinh tế nhằm tìm kiếm lợi nhuận cao nhất, nhanh nhất. Một số nhà nghiên cứu đã chứng minh rằng, Đông Nam Á thành công trong phát triển kinh tế nhưng lại phải hy sinh môi trường.

Những năm gần đây, chúng ta có thể tự hào về sự phát triển kinh tế của nước nhà. Nhưng đáng tiếc mức độ và tần suất các vụ vi phạm pháp luật, các sự cố trong sản xuất gây ra ô nhiễm môi trường cũng tỷ lệ thuận với mức tăng trưởng kinh tế. Trong đó, vụ việc 
Công ty TNHH Gang thép Hưng Nghiệp Formosa Hà Tĩnh vào tháng 4/2016 gây ảnh hưởng nghiêm trọng đến môi trường biển từ Hà Tĩnh đến Thừa Thiên - Huế là một điển hình. Bên cạnh đó, sự thiếu sót của các công trình kiểm soát lũ; chất thải trong hoạt động chăn nuôi động vật, nuôi trồng thủy hải sản không qua xử lý thải vào môi trường; chất hoá học tồn đọng do sử dụng trong trồng trọt ngày càng tăng sẽ làm ảnh hưởng nghiêm trọng đến chất lượng nguồn đất, không khí và đặc biệt là nguồn nước ở nhiều vùng của đất nước. Nguồn gốc sâu xa của những hành động nguy hiểm đó, theo $\mathrm{Ph}$.Ăngghen, là do lợi nhuận tư bản, lợi nhuận thu được trở thành động lực căn bản thúc đẩy các nhà tư bản hành động trái với mọi quy luật, xâm nhập vào mọi ngõ ngách của giới tự nhiên, phá vỡ sự phát triển bình thường của chúng và bất chấp sự trả thù của thiên nhiên.

Thú tu, nạn khai thác tràn lan, kém hiệu quả nguồn khoáng sản tụ nhiên cũng góp phần gây ra một số vấn đề ô nhiễm môi truò̀ng:

Tại Việt Nam, ngành sản xuất vật chất mà phần lớn nguồn nguyên liệu còn phụ thuộc vào tài nguyên thiên nhiên thì đây là một loại vốn không thể thay thế. Bằng sự sáng tạo của trí tuệ và lao động, cùng sự hỗ trợ của kỹ thuật - công nghệ, con người với tư cách một thực thể sinh học - xã hội tác động vào giới tự nhiên với phạm vi và mức độ ngày càng gia tăng. Kết quả điều tra, nghiên cứu về tổn thất trong khai thác, chế biến khoáng sản do Bộ Tài nguyên và Môi trường thực hiện cho thấy: Độ thu hồi quặng vàng trong chế biến (tổng thu hồi) chỉ đạt từ 30 đến $40 \%$; mức độ tổn thất trong khai thác a-pa-tít từ 26 đến 43\%; khai thác quặng kim loại từ $15 \%$ đến $30 \%$; vật liệu xây dựng từ $15 \%$ đến $20 \%{ }^{12}$ Chúng ta chưa nhận thức được khai thác phải đi đôi với tái tạo, tự cho mình quyền được "bóc lột" tự nhiên đến kiệt huệ, đẩy thế hệ sau vào tình trạng "nghèo" tài nguyên.

Bên cạnh đó, công nghệ khai thác lạc hậu đã dẫn đến tình trạng khai thác kèm hiệu quả; cùng với đó là nguồn nước thải từ các khu mỏ có chứa nhiều chất ô nhiễm như As, NH4+, Pb, Fe, Cr, Zn, NO3-, Mn,... được xả thẳng ra môi trường đã tác động xấu tới môi trường đất, nước mặt và nước ngầm. Thật vậy, Để sản

\footnotetext{
${ }^{12} \mathrm{http}: / /$ nhandan.com.vn/xahoi/item/27665002-khai-thac-su-dunghop-ly-tai-nguyen-thien-nhien.html
}

xuất 1 tấn than, cần bóc đi từ $8-10 \mathrm{~m} 3$ đất phủ, thải từ $1-3 \mathrm{~m} 3$ nước thải mỏ ${ }^{13}$. Khối lượng chất thải rắn và nước thải mỏ gây ô nhiễm nặng cho vùng mỏ như Mạo Khê, Uông Bí, Cẩm Phả... Mặc dù chính phủ và các tổ chức bảo vệ môi trường đã có nhiều cố gắng, nỗ lực trong việc kêu gọi sự tiết giảm trong khai thác tài nguyên thiên nhiên và đề cao ý thức bảo vệ môi trường nhằm hướng tới sự bảo tồn và phát triển bền vững nhưng vẫn chưa thu được "quả ngọt".

\section{Thư năm, sụ bùng nổ dân số:}

Trong 5 năm từ 2011-2015 trung bình mỗi năm Việt Nam tăng khoảng 1 triệu người ${ }^{14}$. Dân số nhanh làm gia tăng sức ép đối với tài nguyên thiên nhiên và môi trường sinh thái do phải khai thác tối đa phục vụ cho các nhu cầu sống con người đang từng ngày, từng giờ bóp chết môi trường tự nhiên. Gia tăng dân số đô thị và sự hình thành các thành phố lớn - siêu đô thị do di cư lao động làm cho môi trường khu vực đô thị có nguy cơ bị suy thoái nghiêm trọng. Nguồn cung cấp nước sạch, cây xanh không thể đáp ứng kịp cho sự phát triển dân cư kéo theo ô nhiễm môi trường không khí, nước tăng lên. Ngoài ra, dân số tăng kéo theo gia tăng lưu lượng phương tiện giao thông, tăng lượng khí thải và khói bụi gây ô nhiễm bầu không khí ở các tỉnh, thành phố có mật độ dân số cao đặc biệt là Hà Nội, TP. Hồ Chí Minh.

Thứ sáu, các hoạt động trong chiến tranh để lại nhũng hậu quả lâu dài cho môi truòng:

Chiến tranh là kết cuộc của các mâu thuẫn có nguồn gốc phát sinh từ kinh tế hoặc xã hội hoặc cả hai. Trải qua nhiều thời kỳ lịch sử của chiến tranh, hầu hết đều có một điểm chung đó là sự hoang tàn, hủy diệt bao trùm lên xã hội loài người và đồng thời môi trường tự nhiên cũng chịu ảnh hưởng liên đới bởi những công cụ hủy diệt do chính con người sử dụng thực hiện mục đích chính trị.

Trong chiến tranh xâm lược Việt Nam, đế quốc Mỹ đã rải hàng triệu tấn bom đạn, cùng với hàng triệu lít chất độc hóa học, trong đó chủ yếu là: Chất độc màu da cam, chất trắng dùng để phá huỷ rừng, chất xanh dùng để phá hoại mùa màng. Riêng đối với chất độc màu da

\footnotetext{
${ }^{13}$ http://vea.gov.vn/vn/truyenthong/tapchimt/nctd42009/Pages/Tác độngcủacáchoạtđộngkhaithácmỏđếnnguồnnướcvàhệsinhthái.aspx ${ }^{14}$ BộTàinguyênvà Môitrường (2015),

Báocáohiệntrạngmôitruờngquốcgiagiai đoạn 2011 - 2015, NxbTàinguyên - Môitrườngvà Bản đồViệtNam, Hà Nội, tr 3
} 
cam đây là loại thuốc diệt cỏ rất độc, có chứa hàm lượng lớn chất dioxin, khó phân hủy, gây chết thực vật, làm ô nhiễm nguồn đất, nước, hủy hoại nghiêm trọng môi trường sinh thái ở đất nước ta, không những trong quá khứ mà vẫn duy trì đến hiện nay.

Thư bảy,biến đổi khi hậu là nguyên nhân dẫn đến tình trạng thiên tai đã tác động không tốt đến môi truòng tụ nhiên:

Biến đổi khí hậu đang tác động trực tiếp lên môi trường. Cụ thể, trong thời gian gần đây thiên tai và các hiện tượng khí hậu cực đoan diễn ra thường xuyên đã gây ra các thảm họa về môi trường. Viễn cảnh cho thấy, lũ lụt, bão tố liên tiếp xuất hiện là thời cơ, là "bàn tay” đầy sức mạnh giúp các chất độc hại tích tụ “đang ngủ say” trong môi trường "bừng tỉnh", có điều kiện phát tán và gây bất lợi cho môi trường. Bên cạnh đó, tình trạng hạn hán do biến đổi khí hậu gây ra một số tác động xấu lên môi trường như: nhiệt độ tăng cao dẫn đến tình trạng cháy rừng sinh ra nhiều tro và bụi, $\mathrm{CO} 2, \mathrm{CO}, \ldots$ gây ô nhiễm bầu không khí; khô hạn kéo dài dẫn đến thiếu nước ngọt, môi trường đất không được rửa trôi và trở nên hoang hóa...

\subsection{Kết quả}

"Gieo nhân nào thì gặt quả nấy" - đấy là nguyên lý của cuộc sống. Con người và tự nhiên luôn có mối liên hệ gắn bó chặt chẽ trong quá trình sống, phát triển. Khi sự cân bằng giữa con người và môi trường tự nhiên bị phá vỡ, khi những hoạt động chinh phục, cải biến đi quá giới hạn chịu đựng của tự nhiên khi đó con người sẽ phải đứng trước "sự trả thù của tự nhiên". Theo quy luật, môi trường sẽ đáp trả tương ứng với cách mà con người từng cư xử với nó, cụ thể là:

Một là, khi môi truòng ô nhiếm sẽ ảnh huởng nghiêm trọng đến sức khỏe, tính mạng con người:

Trong tác phẩm "Biện chứng của tự nhiên", Ph.Ăngghen đã phân tích sự tương tác và chế ước lẫn nhau trong một thể thống nhất giữa con người và tự nhiên; con người không chỉ tác động, cải biến tự nhiên mà tự nhiên cũng tác động ngược trở lại con người. Cho nên, $\mathrm{Ph}$.Ăngghen đã cảnh báo khoa học "không nên quá tự hào về những thắng lợi của chúng ta đối với giới tự nhiên. Bởi vì, cứ mỗi lần ta đạt được một thắng lợi, là mỗi lần giới tự nhiên trả thù lại chúng ta""15.

${ }^{15}$ C.Mácvà Ph. Ăngghen (1995), Toàntập, NxbChínhtrịQuốcgia, tập $20, \operatorname{tr} 654$
Các nhân tố bất lợi do con người đưa vào môi trường tự nhiên gây ra ô nhiễm, thì môi trường bị ô nhiễm cũng sẽ sản sinh "quả xấu" theo con đường tự nhiên xâm nhập cơ thể con người gây ra những căn bệnh vô cùng nguy hiểm, thậm chí những hệ lụy đó sẽ di truyền cho các thế hệ sau. Thiên nhiên đang giận dữ và trực tiếp trút tai họa xuống con người khi con người không đồng hành với quy luật của nó. Thật vậy, tình trạng nguồn không khí, nguồn nước, đất đai bị ô nhiễm, các hiện tượng thiên tai do biến đổi khí hậu xuất hiện trở nên phổ biến, xảy ra ở nhiều vùng miền đang ảnh hưởng nghiêm trọng, trực tiếp đến mọi người; đã cướp đi nguồn sống qúy giá, gây thiệt hại lớn về vật chất và tinh thần, sức khỏe và tính mạng, việc làm và đời sống của biết bao con người.

Con người được xác định là trung tâm của mọi vấn đề, suy cho cùng tấc cả mọi hoạt động đều thực hiện vì con người.Tuy nhiên, chỉ tập trung chăm lo cho con người, "bóc lột" môi trường thì có nghĩa là chúng ta đang tự trồng "quả xấu" để thu hoạch. Việc chúng ta tác động vào môi trường như đang sử dụng con "dao hai lưỡi", một lưỡi dùng để khoét sâu những tổn thương và giết chết môi trường tự nhiên, một lưỡi chúng ta tự cắt vào thân thể của chính mình.

Hai là, nhũng thiệt hại về môi trường là gánh nặng cho nền kinh tế, xã hội:

C.Mác viết: "Những thời đại kinh tế khác nhau không phải ở chỗ chúng sản xuất ra cái gì, mà là ở chỗ chúng sản xuất bằng cách nào, với những tư liệu lao động nào"16. Chế độ xã hội quy định tính chất, mục tiêu, phương hướng của con người trong quá trình tác động vào giới tự nhiên. Ở Việt Nam, chính sách đổi mới bắt đầu năm 1986 đã mang lại tốc độ tăng trưởng kinh tế tương đối nhanh, nhưng chi phí môi trường cũng cao.

Theo nhiều chuyên gia trong và ngoài nước, với mô hình kinh tế như hiện nay, nếu GDP Việt Nam tăng gấp đôi, thì ô nhiễm môi trường sẽ tăng gấp ba lần; tăng 1\% GDP thì thiệt hại do ô nhiễm môi trường sẽ làm mất đi $3 \%$ GDP; riêng tỷ lệ chi trả để bảo vệ chăm sóc sức khỏe của năm 2020 sẽ lên tới $1,2 \%$ GDP, tăng 4 lần so với năm ${ }^{17}$. Ước tính trong 4 năm trở lại đây, chúng ta phải chi đến khoảng 20 triệu USD

\footnotetext{
${ }^{16}$ Sđd, tập 23, tr 269

${ }^{17}$ Tríchtrong: Môitrường - SOS
} 
(khoảng 400 tỷ đồng) chủ yếu là điều trị các bệnh do ô nhiễm môi trường gây $\mathrm{ra}^{18}$.

Ô nhiễm môi trường đất, nước, các sự cố môi trường biển... xảy ra trong thời gian qua đã làm cho động thực vật trong tự nhiên và trong nuôi trồng chết hàng loạt, gây ra tổn thất nặng nề cho nền kinh tế. Tính riêng vụ Formosa, Chính phủ chỉ rõ "Hệ sinh thái biển bị ảnh hưởng nghiêm trọng" thiệt hại khoảng 100 tấn cá chết, 17.600 tàu cá và gần 41.000 người đã bị ảnh hưởng trực tiếp, hàng ngàn lồng nuôi cá cũng bị thiệt hại, giảm nguồn thu du lịch khoảng 40-50\% do khách hủy tour... ${ }^{19}$. Ở một khía cạnh khác, hiện tượng xâm nhập mặn diễn ra làm cho hoạt động sản xuất và đời sống của người dân gặp nhiều khó khăn; đất nhiễm mặn dẫn đến nhiều diện tích cây trồng bị thu hẹp, thủy sản chết do nước biển lấn sâu vào sông ngòi, ao hồ, người dân thiếu nước ngọt sinh hoạt. Từ đó, nhiều vấn đề phát sinh như: nước ngọt trở nên khan hiếm và đắt đỏ, giá lúa gạo liên tục biến động, giá thực phẩm và thủy sản tăng mạnh... làm cho nền kinh tế bất ổn, giá cả biến động thất thườg, mất cân đối trong cung cầu và phát sinh chi phí khắc phục sự cố rất cao.

Thực tiễn vừa nêu chỉ mới là phần nổi của vấn đề, tuy nhiên cũng đã vẽ được bức tranh tiệm cận về thiệt hại kinh tế, việc tiêu tốn ngân sách cho xử lý, khắc phục những hậu quả của ô nhiễm môi trường là không hề nhỏ. Chúng ta phải ý thức được rằng: xã hội tiến bộ, kinh tế phát triển là quan trọng nhưng cần thiết hơn hết là phải tăng mức an sinh con người. Do đó, phải có sự hài hòa giữa mục tiêu tăng trưởng kinh tế xã hội song song với bảo vệ môi trường.

Thư ba, cạn kiệt tài nguyên thiên nhiên, mất cân bằng hệ sinh thái:

Ngày nay, với khoa học và công nghệ hiện đại, con người đã có thể tạo ra tài nguyên nhân tạo. Song, suy cho cùng, nguồn gốc của nguyên liệu tạo nên chúng đều xuất phát từ tự nhiên. Vì vậy, tự nhiên luôn là nền tảng, là điều kiện tồn tại và phát triển của xã hội. Kinh tế phát triển nhanh chóng, dân số tăng, nhu cầu tài nguyên phục vụ sản xuất cao, kèm theo đó là nạn khai thác tràn

\footnotetext{
${ }^{18}$ BộTàinguyênvà Môitrường (2015),

Báocáohiệntrạngmôitruò̀ngquốcgiagiai đoạn 2011 - 2015, NxbTàinguyên - Môitrườngvà Bản đồViệtNam, Hà Nội, tr 176

${ }^{19} \mathrm{https}$ //tuoitre.vn/chinh-phu-cong-bo-chi-tiet-thiet-hai-do-formosagay-ra-1145284.htm
}

lan, không có kế hoạch, định hướng chiến lược, không thắt chặt quản lý thì việc cạn kiệt tài nguyên thiên nhiên (rừng, đất, khoáng sản, động thực vật,...) sẽ không còn quá xa. Giám đốc PanNature - Ông Trịnh Lê Nguyên đưa ra lời cảnh báo cho mọi người rằng: "Nhiều loại khoáng sản của Việt Nam sẽ cạn kiệt trong tương lai gần" ${ }^{20}$. Cụ thể, số năm khai thác còn lại của dầu khí là 56 năm, barit là 21 năm, thiếc là 19 năm, chì - kẽm là 17 năm và vàng là 21 năm.

Bên cạnh đó, môi trường sống bị huỷ hoại, khai thác tận diệt, thiên tai liên tiếp... đã làm cho nguồn động thực vật bị thu hẹp cả về số lượng, chất lượng và mất cân bằng hệ sinh thái tự nhiên. Theo thống kê, ở Việt Nam có khoảng 100 loài thực vật và gần 100 loài động vật đang đứng trước nguy cơ tuyệt chủng do ô nhiễm môi trường gây ra. Vì mục tiêu kinh tế ngắn hạn mà con người từ bỏ lợi ích dài hạn, vì lòng tham vô hạn mà gây hại đến môi trường tự nhiên, mọi sinh vật hiện tại và cả thế hệ tương lai đang sống dựa vào tự nhiên.

Thư tu, ô nhiễm môi trường sẽ là mối đe dọa đến sự thịnh vương của quốc gia:

Trong lịch sử xã hội từng có những nền văn minh một thời phát triển rực rỡ, huy hoàng, nhưng đã phải tiêu vong do sự tác động quá mức của con người đối với môi trường tự nhiên. Điển hình trong số đó là nền văn minh Mayas mà "lý do làm cho nền văn minh này sụp đổ sau hơn 15 thế kỷ hưng thịnh là nền độc canh và đốt rừng tràn lan để lấy đất làm rẫy. Cả hai phương thức đó làm cho đất đai bạc màu, gây hạn hán, lụt lội và phá hủy mùa màng. Vì vậy, đền đài đồ sộ của người Mayas còn đó nhưng có gì để nuôi sống họ nữa đâu. Thế là một trang sử đã bị lật qua và người Mayas phải chịu cảnh phiêu bạt, bị đế quốc khác thống trị’”21. Một quốc gia sẽ không thể vững mạnh và phát triển bền vững nếu các mối đe dọa về kinh tế, môi trường, con người luôn tồn tại và ngày càng gia tăng. Bởi các yếu tố đó là nguồn gốc sức mạnh, là động lực thúc đầy của sự thay đổi và tiến bộ.

Thứ năm, môi truờng ô nhiếm sản sinh ra nhiều hậu quả nghiêm trọng và đồng thời nhũng hậu quả đó

\footnotetext{
${ }^{20} \mathrm{http}$ //www.sggp.org.vn /nhieu-loai-khoang-san-cua-viet-nam-secan-kiet-trong-tuong-lai-gan-340236.html

${ }^{21}$ Nguyễn Trọng Chuẩn (1980), "Những tư tưởng của Ph. Ăngghen về quan hệ giữa con người và tự nhiên trong "Biện chứng của tự nhiên”, Tạp chí Triết học, số 4, tr 127
} 
sẽ tác động ngược trở lại làm cho môi truờng trở nên xấu hơn:

Một khi sức khỏe cá nhân bị ảnh hưởng, nền kinh tế mà con người đang tập trung theo đuổi bị de dọa bởi môi trường ô nhiễm thì con người sẽ không còn thời gian để quan tâm đến các khía cạnh khác; bởi lẽ, theo con người thiển cận thì đây là những yếu tố cần thiết nhất cho sự sống. Cho nên, con người với cái tôi cá nhân đã chi phối mạnh mẽ tới hành động, con người chỉ biết chú tâm giải quyết những vấn đề khó khăn trước mắt mà mà không suy xét đến cái gốc của vấn đề để giải quyết triệt để, đồng nghĩa con người sẽ tiếp tục "buông lỏng" việc bảo vệ môi trường và tất nhiên là nó sẽ trở nên xấu đi với mức độ tỷ lệ thuận theo thời gian bị lãng quên. Mặt khác, tài nguyên thiên nhiên cạn kiệt, môi trường sinh thái bị phá hủy sẽ xuất hiện tâm lý "tranh thủ thu lợi"; từ đó dẫn đến môi trường càng thêm ô nhiễm, kiệt huệ đến "cùng cực" thay vì được chăm lo cải thiện. Ô nhiễm môi trường gây ra những hậu quả nghiêm trọng về nhiều mặt. Tuy nhiên, chưa dừng lại ở đó, những hậu quả xấu sẽ tiếp tục tác động đến tâm lý, ý thức và chính sự tác động đó sẽ tiếp tục là nguyên nhân trở lại ảnh hưởng đến sự trong lành của môi trường theo một vòng luẩn quẩn.

\section{Kết luận và giải pháp}

Sở dĩ ngày nay chúng ta luôn sống trong các mối đe doạ từ thiên tai, bệnh tật, nghèo đói, chậm phát triển đều xuất phát từ những hậu quả ô nhiễm môi trường và nguyên nhân là do thái độ sống, cách chúng ta giao tiếp với môi trường tự nhiên. Chúng ta đã có quá nhiều sai lầm, tư tưởng ích kỉ, sống ngược với quy luật tự nhiên nên việc tự nhiên "đáp trả” lại chúng ta là điều tất yếu, là "quả xấu" con người phải nhận lãnh từ việc gieo "nhân dữ". Từ đó, do tính thống nhất của hệ thống "Tự nhiên - Con người - Xã hội” đòi hỏi việc giải quyết và thực hiện công tác quản lý môi trường phải toàn diện và hệ thống. Có thể nói, vấn đề môi trường hiện nay là hết sức cấp thiết, buộc mọi con người phải suy nghĩ và hành động ngay khi chưa quá muộn. Tuy tình trạng ô nhiễm môi trường ở Việt Nam ở mức đáng báo động nhưng vẫn còn có thể cứu vãn nếu chúng ta thực hiện các giải pháp sau:

Truớc tiên, chú trọng giáo dục ý thức, trách nhiệm bảo vệ môi truòng trong toàn xã họi:

Cần quán triệt và giáo dục với mọi đối tượng trong nhân dân quan điểm của chủ nghĩa Mác-Lênin, tư tưởng Hồ Chí Minh về con người, tự nhiên, về mối quan hệ con người với tự nhiên, quan điểm sống hài hòa với thiên nhiên như một giá trị văn hóa. Đồng thời, tích cực, mạnh dạn đấu tranh, phê phán các tư tưởng hẹp hòi, khuynh hướng tuyệt đối hoá tầm quan trọng của con người, con người sống ngoài tự nhiên, không phụ thuộc vào tự nhiên. Đẩy mạnh lồng ghép nội dung vào chương trình học nhằm nâng cao ý thức về bảo vệ môi trường cho thế hệ trẻ.

Tiếp theo, xây dụng, hoàn thiện hệ thống pháp luật về môi trường:

Nhà nước, các tổ chức chuyên trách tiếp tục xây dựng, hoàn thiện hệ thống pháp luật, hành lang pháp lý về bảo vệ môi trường, phải đảm bảo sự đồng bộ, thống nhất, cụ thể, bám sát thực tế. Phải tăng cường sức mạnh chế tài, các hình thức xử lý và đảm bảo tính thực thi của pháp luật. Từ đó, tập trung tiến hành tổ chức quán triệt, học tập, bồi dưỡng cho các cơ quan và đội ngũ cán bộ, nhân viên chuyên trách về môi trường để không ngừng lớn mạnh, đáp ứng yêu cầu ngày càng cao của thực tiễn bảo vệ, gìn giữ môi trường.

Cuối cùng, tổ chức thục hiện các hoạt động bảo vệ môi truòng:

Đẩy mạnh các hoạt động hưởng ứng ngày môi trường thế giới. Tổ chức và vận động mọi người cùng nhau tham gia các hoạt động bảo vệ môi trường như trồng cây xanh, thu gom rác thải, vệ sinh cống rãnh...Tại các khu du lịch, khu đông dân cư, tuyến đường lớn, khu ăn uống, vui chơi... nên bổ sung thêm nhiều thùng rác và các nhà vệ sinh công cộng. Kết hợp các ban ngành, đoàn thể xây dựng phong trào bảo vệ môi trường trong tất cả các cơ quan, tổ chức và toàn xã hội.

\section{TÀI LIỆ THAM KHẢO}

1. Bộ Tài nguyên và Môi trường (2015), Báo cáo hiện trạng môi truò̀ng quốc gia giai đoạn 2011 - 2015 , Nxb Tài nguyên - Môi trường và Bản đồ Việt Nam, Hà Nội;

2. Nguyễn Thế Chinh (2017), "Môi trương Việt Nam: Thực trạng, nguyên nhân và một số kiến nghị”, Tạp chí Khu công nghiệp Việt Nam, truy cập ngày 02/7/2018,

http://khucongnghiep.com.vn/nghiencuu/tabid/69/artic leType/ArticleView/articleId/1916/Default.aspx;

3. Nguyễn Trọng Chuẩn (1980), "Nhũng tu tuởng của Ph. Angghen về quan hệ giũa con ngườ và tụ nhiên trong "Biện chưng của tụ nhiên”, Tạp chí Triết học, số 4 , tr. 127 ; 
4. C.Mác và Ph.Ăngghen (1995), Toàn tập Nxb Chính trị Quốc gia, (Tập 20, 23, 42), Hà Nội;
5. Đào Duy Thanh \& cộng sự (2004), Triết học Mác Lênin - Đề cuơng bài giảng và huớng dẫn ôn tập, Nxb Chính trị quốc gia, TP. Hồ Chí Minh.

\section{The application of causes - results on analysis of environmental pollution problems in Vietnam}

\section{Tran Bao Nguyen, Duong Huyen Trang}

\section{Article info}

Recieved:

$02 / 8 / 2018$

Accepted:

10/9/2018

Keywords:

Environmental, pollution, relationship, cause, results.

\begin{abstract}
Environmental protection is an important issue and critical for sustainable development and future of human. The article is based on the "cause - results" relationship, focuses on analyzing the causes of the more and more serious environmental degradation and indicators the disastrous issues due to environmental pollution. The results show that natural factors, lack of human consciousness in production and living, and past war effects are principal causes of environmental pollution. As a result, polluted environment will reimpact human beings, and we will face health risks, resource shortages, heavy economic losses, these will cause slow-developing countries. As evaluated above, some possible solutions to lessen problems of environmental pollution can be brought out and discussed.
\end{abstract}

